Teresa M. Sgaramella*, Laura Nota, Loredana Carrieri, Salvatore Soresi and Giovanni Sato

\title{
Daily functioning, problem solving and satisfaction for quality of life in visually impaired old persons
}

DOI 10.1515/ijdhd-2016-0010

Received February 8, 2016; accepted May 1, 2016

\section{Abstract}

Aim: The purpose of this study was to investigate the impact of several dimensions of functioning on satisfaction for quality of life (QoL) experienced by visually impaired older adults.

Participants: A sample of 58 older adults (37 women and 21 men) was involved in the study. Their age ranged from 50 to 88 years $(M=68.95, S D=1.51)$. They were characterized by visual impairment of different origin and visual acuity (VA) ranging from 4/10 to total blindness. The QoL questionnaire was used along with short form-12 health Survey, the National Eye Institute visual function questionnaire-25 and problem solving inventory (PSI) which analyzes problem solving appraisal.

Results: A stepwise regression analysis was conducted in order to find predictors of satisfaction for QoL. A contribution of mental and physical health, more specifically, of problem solving appraisal was found.

Conclusion: Results support the notion that the functional relationship between visual impairment and satisfaction for QoL must be understood in terms of approaches that incorporate psychological and socio-cognitive elements. Problem solving appraisal, in fact, makes a substantial contribution to the prediction of variance in life

\footnotetext{
*Corresponding author: Teresa M. Sgaramella, Department of Philosophy Sociology, Education and Applied Psychology (FISPPA), and Center for Disability and Inclusion, University of Padova, Via Venezia 14, 35131 Padova, Italy, Phone: +39 498278458 , Fax: +39 49 8271297, E-mail: teresamaria.sgaramella@unipd.it. http://orcid.org/0000-0001-9041-1011 Laura Nota and Salvatore Soresi: Department of Philosophy Sociology, Education and Applied Psychology (FISPPA), and Center for Disability and Inclusion, University of Padova, Italy Loredana Carrieri: Center for Disability and Inclusion, University of Padova, Italy Giovanni Sato: Regional Center for the Rehabilitation of Vision, Padova, Italy
}

satisfaction and it may play an important role for intervention strategies.

Keywords: daily functioning; mental and physical health; older adults; problem solving appraisal and satisfaction for quality of life; visually impaired.

\section{Introduction}

It has been generally recognized that dealing with visual impairments can result in a loss of independence, of mobility or in a reduced ability to participate in everyday activities [1, 2]. Vision loss, in fact, can restrict spatial orientation and the ability to perform daily tasks such as reading, writing, and driving, which can subsequently lead to social, economic, and personal consequences [3-5].

As vision loss increases with increasing age, the role of aging has been repeatedly analyzed and contrasting results have been reported in the literature. According to some authors, visual loss may amplify difficulties generally ascribed to old age, such as a reduction of independence in daily functioning or diminished activity or on psychosocial functioning $[3,6,7]$. On the other hand, Kleinschmidt [8] suggested that elderly people have various perceptions of what good adjustment means. Old persons generally have a positive outlook on life despite their sensory loss: they tend, for instance, to believe that visual loss is expected in later life and often ignore disturbances which impact worsening vision [9]. Additionally, as a result of resilience, of accumulated flexibility and coping skills in dealing with everyday problems, they report a life satisfaction higher than younger age cohorts with visual impairment or older sighted cohorts [10, 11]. Research studies seem, then, to support the idea of a non specific role of aging on quality of life (QoL) perceived by old persons with visual impairment and encourage the investigation of the potential role of other dimensions, at the same time paying attention to both the physical and mental status and daily functioning, and problem solving and to their relationship with perceived QoL. 
Several studies have analyzed the association between visual impairment, physical and/or mental status, and daily functioning. These studies usually are based on Health Survey Questionnaire, known as SF-36 [12], a general health status questionnaire, and on the National Eye Institute visual function questionnaire [13] which measures the impact of vision in task oriented domains related to daily VFQ. When studying perceived physical and mental status, visually impaired individuals report poorer health status with more severe impairment [14-17]. Additionally, they seem to be at increased risk for disabling outcomes such as falls, injury, accidents, inability to drive, social dependence and increased mortality [18-20]. Lamoureux et al. [21] have examined the interaction of visual, demographic, personal, cultural and environmental influences on vision related functioning. Besides the SF 36, they used a specific health related questionnaire, the impact of vision impairment (IVI). Distance visual acuity (VA), mental and physical health predicted participation in daily life of these individuals. As the authors also emphasized, two of these determinants, namely mental and physical health, can be affected by changes and can be seen as potential targets for rehabilitation interventions.

Moreover, according to the literature, problem solving skills may play a significant role in adaptation to disability following visual damage [22]. Problem solving has been defined as the complex inter-play of cognitive, affective, and behavioral processes for the purpose of adapting to internal or external demands or challenges [23]. It involves both problem orientation, and problem solving with the first usually referring to the general attitude of individuals towards problems and the second referring to coping with a problematic situation. In particular, problem solving appraisal has been demonstrated to influence a wide variety of psychological adjustment variables and to both physical and psychological wellbeing such as, for instance, depression, self-esteem, anxiety, dysfunctional thoughts, health expectancies and health complications [24, 25]. With respect to visually impaired individuals, a proactive problem-solving perspective seems to help individuals finding creative solutions to difficulties they encounter following vision loss [26]. Planful coping strategies are associated with less distress [27] while a negative problem orientation uniquely predicts domain-specific emotional distress, depressive symptoms, well-being and functional abilities reported by persons in a low vision rehabilitation program [22]. No further investigations have been conducted, to our knowledge, on its role on satisfaction for QoL.
Additionally, as regards QoL, we will refer here to a multidimensional construct which is composed by several domains such as emotional well-being, material and physical well-being, interpersonal relationship, personal and professional development, self-determination, social inclusion and supports, residential environment [28-30]. Finally, both objective and subjective aspects, together with life satisfaction experienced in domains mentioned above are taken into account [31-33].

As far as several factors seem to play a role in QoL experienced by visually impaired individuals, LaGrow et al. [34] in a longitudinal study of old persons analyzed the extent to which 11 different variables (e.g. age, sex, ability to see newsprint, satisfaction with ability to perform activities of daily living, ability to get around, feelings of social isolation or loneliness, and life satisfaction) affected perceived QoL. Measures of physical and mental health derived from the SF-36 and four scaled scores describing economic living standards (economic standing, mental and physical health, and social provisions) were included and considered as measures of QoL although they address 'health related' QoL. As expected, those who reported difficulty in seeing newsprint were found to score worse in their satisfaction with everyday activities; they also had more concomitant health problems, lower mental and physical health and lower QoL with respect to those who did not have difficulties in seeing. A standard regression analysis conducted on scores obtained by participants who reported difficulty with seeing ordinary newsprint showed that ability to get around and diagnosed health conditions significantly predicted their perceived life satisfaction. The study mentioned highlights the relationship between visual impairment and perceived physical disability, and also between visual impairment and perceived mental difficulties; additionally, the role of these variables on satisfaction for health-related QoL. A role of problem solving skills on QoL of persons with visual impairment is also suggested by the authors. Studies analyzing the relationship between vision impairment, perceived physical and mental status, daily functioning, and both problem solving and satisfaction for QoL experienced in several life domains as analyzed not in health-related terms are still lacking in the literature.

Considering all that, the study presented here involved elderly individuals with marked or severe visual impairment. Perceived physical and mental disability, i.e. the health status, were both taken into account, together with problem solving abilities they recognize themselves. Although the role of these variables on satisfaction for QoL is generally recognized, it is problem solving which is expected to show a significant predictive role for this 
dimension of well-being. Evidence for the role of problem solving will provide suggestions for counseling activities to be provided to older persons with visual impairment.

\section{Methods}

\section{Participants}

Study participants were 58 adults, 37 women (63.8\%) and 21 men (36.2\%). Their age ranged from 50 to 88 years $(M=68.95, S D=1.51)$. They were recruited in a specialized low-vision rehabilitation center in the province of Padova, in the northeast of Italy. Written consent to participation in the observational study was given to the rehabilitation center team by each study participant. Research had also been proposed and approved by the institution committee. Written consent to participation in observational study had already been given by each study participants.

Inclusion criteria were: no cognitive or communication or auditory impairment, $\mathrm{VA}<5 / 10$ in the better eye, Italian speaking and being 50 years or older. According to Italian criteria on visual impairment stated by Ministry of Health, three participants (5.2\%) had total blindness, 24 (41.4\%) were partially blind, 10 (17.2\%) were classified as having severe visual impairment, 12 (20.7\%) were classified as having moderate visual impairment and $3(5.2 \%)$ were classified as having mild visual impairment. In addition, six of them (10.3\%) had VA ranging from 4 to 5/10 in the better eye and classified as having visual difficulties and included in the study. Participants were characterized by several different types of visual impairment, the most frequent being vascular age-related macular degeneration (24.1\%), atrophic age-related macular degeneration (20.7\%), myopic macular degeneration (22.4\%), diabetic retinopathy (10.3\%), glaucoma (6.9\%) and hereditary macular dystrophy (6.9\%).

\section{Instruments}

Short form health survey (SF-12): The SF-12 [35, 36] is a shorter version of the SF-36 [37]. As regards physical disabilities physical composite score (PCS), answers to six items are provided on a three-point Likert scale ranging from "yes, limited a lot" to "no, not limited at all". Six items analyze the mental status mental composite score (MCS). Answers are provided on a five-point Likert scale ranging from "all of the time" to "none of the time". Higher scores for both subscales reflect better health. For this study $\alpha$ reached, respectively, 0.78 and 0.74. A factorial analysis, conducted using the principal component analysis with orthogonal rotation, confirmed for the Italian version two factors, a physical and a mental component, which explained a total variance of $67 \%$ [38].

Visual function questionnaire-25 (VFQ-25) [13]: This is a short version of the original National Eye Institute visual function questionnaire-51 (NEI VFQ-51) [39], developed to measure the effects of eye diseases on a daily VFQ. Items of the VFQ-25 mainly measure performance or frequency and are grouped into 12 subscales: general health, general vision, near and distance vision, peripheral vision, color vision, ocular pain, role difficulties, dependency, social functioning, driving difficulties. First of all, original numeric values from the survey were re-coded in a $0-100$ scale so that the lowest and highest possible scores were set at 0 and 100 points, respectively. A score can be calculated for the instrument as a whole (total score) or for each separate subscale.

High internal consistency of the original instrument was found by Margolis et al. [40]. The Italian version of the instrument shows comparable psychometric properties [41]. Internal consistency estimates for each subscale ranged from 0.71 to 0.85 [13]. For this study, selected items and subscales related to functional activities of daily VFQ were used ( $\alpha=0.89$ ), addressing problems related to near vision (three items), distance vision (three items), peripheral vision (one item), color vision (one item) and social functioning (two items). As far as the driving the subscale did not apply for the majority of participants, and it was excluded from the analysis. Answer alternatives ranged from no difficulty at all to stopped doing this for other reasons or not interested in doing this.

Problem solving inventory (PSI): PSI is a 35-item inventory assesses individual problem-solving appraisal [42-44]. It is composed of three factors and a total score is derived by the sum of the three factors. People are asked to rate on a six-point Likert scale their level of agreement with the sentences of the instrument (from 1=strongly agree to $6=$ strongly disagree). Higher scores indicate an individual's assessment of oneself as a relatively ineffective problem solver. The first factor is problem solving confidence (11 items) and refers to the individual's belief and trust in one's own problem solving ability. The second factor, the approach/ avoidance style, refers to problem solving style and is defined as a general tendency to approach or avoid a wide range of problem solving activities (16 items). The last factor, the personal control, refers to the individual's belief that one is in control of his or her own behaviors and emotions while solving problems (five items). The PSI was translated into Italian by two native-Italian speakers who are fluent in English and achieved a shared Italian version of each. Next, the Italian translations were back-translated by a professional Italian-English translator. Once back-translation was complete, the professional Italian-English translator and another native Italian speaker fluent in English compared each back-translated item to the original English items and semantic equivalence or meaning was needed and achieved for four items. The PSI's psychometric estimates were analyzed with a large sample of participants across geographically representative regions of Italy. Results revealed a similar but slightly different PSI factor structure in the Italian PSI. The Italian version of PSI has acceptable internal consistency estimates ( $\alpha$ coefficient ranging from low $0.70 \mathrm{~s}$ to high $0.80 \mathrm{~s}$ ) and good stability estimates (test-retest reliability coefficients) of 0.80 over a 2-week period and 0.81 over 3 weeks as well as 4 months. For the purpose of this study a PSI total score was used $(\alpha=0.85)$.

QoL questionnaire [28]: The version used in this study analyzes satisfaction for QoL throughout eight different domains. Answers are rated on a five-point scale ranging from "not satisfied at all" to "very satisfied". The 35 items are grouped into several subscales addressing satisfaction for family relationships (seven items; $\alpha=0.91$ ), for well-being (four items, $\alpha=0.83$ ), for social supports (four items, $\alpha=0.77$ ), for professional development (four items, $\alpha=0.95$ ), for economic status (three items, $\alpha=0.74$ ), for self-determination (six items; $\alpha=0.73$ ), for supports from social services (four items, $\alpha=0.81$ ), for residential environment (three items, $\alpha=0.61$ ). 
A total score was used in this study $(\alpha=0.90)$ summing up answers provided by subjects on each subscale. Internal consistency estimates and stability estimates have been reported in previsous studies together with descriptions of different profiles observed with specific components affected $[28,45]$.

\section{Procedure}

Administration of the instruments was conducted by an expert psychologist working in the low-vision rehabilitation center after being approved by the appropriate Ethics Committee. All participants were interviewed face to face after they signed an informed consent form. Information on VA and clinical history were collected from patients' clinical records; personal and environmental data were collected by the psychologist before starting the assessment. Two different sessions, each lasting approximately $1 \mathrm{~h}$, were implemented. The items of each questionnaire, together with the instructions and the encoding of answers, were read one by one by the psychologist. A personalized report on the individual results was also provided to each participant and recorded on a $\mathrm{CD}$ if required.

\section{Data analysis}

First of all descriptive statistics and correlation analyses were performed to examine, as suggested in the literature, the possible role of demographic variables and to explore the relationship between the dimensions addressed by the study.

According to the research questions, a stepwise regression analysis was performed. PCS and MCS and mean score in the daily VFQ subscale (analyzing near vision, distance vision, social functioning, peripheral vision and color vision) were entered into the equation, respectively, as the first and second step; then, as a third step, the PSI total score was entered to highlight the incremental gain in the variance explained and the more crucial role of problem solving skills over health and functional consequences on well-being [22, 24, 25] and more particularly on satisfaction for QoL experienced. All variables were forced into the model. All data analyses were performed using SPSS version 22.0 for Windows software [46].

\section{Results}

\section{Preliminary analyses}

Table 1 summarizes results from descriptive analyses. Several preliminary analyses of variance were conducted in order to investigate the possible role of age, gender and education. No significant differences were found on SF-12 subscales, VFQ and PSI scores when dividing subjects in two groups according to age (up to 60 vs. over 60 years old; respectively, PSC: $F=0,851$, df 1,56; $p$ 0.336; MCS: $F=0,057$, df 1,56, n.s.; VFQ: $F=0,002$, df 1,56, n.s.; QoL: $F=0,600$, df
1,56, n.s. and total PSI score $F=0,323$, df 1,56, n.s.), gender (respectively, PSC: $\mathrm{F}=0,354$, df 1,56, n.s.; MCS: $\mathrm{F}=4,08$, df 1,56, n.s.; VFQ: $F=0,027$, df 1,56, n.s.; QoL: $F=1,042$, df 1,56, n.s.; 0.312 and total PSI score: $F=0,062$, df 1,56, n.s.) or education (up to 8 years vs. 13 or more years of education; respectively PSC: $F=0,829$ df 1,56; n.s.; MCS: $F=1,193$, df 1,56, n.s.; VFQ: $F=3,223$, df 1,56, n.s.; QoL: $F=3,23$, df 1,56; n.s. and total PSI score: $F=3,58$, df 1,56, n.s.). Given the absence of significant differences, study participants were then considered as a single group for subsequent analyses.

Pearson correlations among life satisfaction, problem solving appraisal, daily VFQ, physical and mental health were then conducted. As we can see in Table 1, there are some moderate significant negative correlations between satisfaction for QoL and problem solving appraisal $(\mathrm{r}=0.304, \mathrm{p}<0.05)$. As higher scores in PSI describe a lower problem solving appraisal while higher scores in the QoL questionnaire indicate higher satisfaction, the significant negative correlation suggests that higher problem solving appraisal is related to higher life satisfaction. In addition, there are also significant positive correlations between both satisfaction for QoL and respectively daily VFQ $(\mathrm{r}=0.266 ; \mathrm{p}<0.05)$ and mental health $(\mathrm{r}=0.309 ; \mathrm{p}<0.05)$. Finally, daily VFQ significantly correlates with both mental $(r=0.279 ; p<0.05)$ and physical health $(r=0.369$; $\mathrm{p}<0.01)$.

\section{Predictors of satisfaction for quality of life}

In order to analyze the contribution of mental and physical health, investigated by SF-12, together with daily VFQ, and of problem solving appraisal in determining satisfaction for QoL, a stepwise regression analysis was carried out (Table 2).

In the first step, physical component score and mental component score (PCS and MCS) were entered; then, as a second step the mean score obtained on subscales related to task-oriented domains in daily VFQ (near vision, distance vision, social functioning, peripheral vision, color vision) was entered; finally, as a third step PSI total score was entered.

When the PCS and MCS scores were entered, the model was significant, $F(1,56)=5.93, p<0.05)$, and accounted for $9.6 \%$ of the total variance. Only MCS was a significant predictor $[\beta=0.309, t(63)=2.44, p<0.05]$. In the second step the daily VFQ component was entered; the model was also significant, $F(2,55)=4.14, \mathrm{p}<0.05)$, and accounted for $13 \%$ of the total variance. Mental health was a marginally unique predictor $(\beta=0.195, t(63)=1.49, \mathrm{p}=0.056)$. $R^{2}$ change between the two models was not significant 
Table 1: Descriptive statistics and intercorrelations among satisfaction for QoL, problem solving appraisal, daily visual functioning and physical and mental health.

\begin{tabular}{|c|c|c|c|c|c|c|c|}
\hline & M & SD & 1 & 2 & 3 & 4 & 5 \\
\hline 1. Satisfaction for QoL & 125.09 & 16.82 & - & $-0.304^{b}$ & $0.266^{\mathrm{b}}$ & $0.309^{b}$ & 0.106 \\
\hline 2. Problem solving inventory & 84.43 & 19.62 & & - & -0.145 & -0.093 & -0.045 \\
\hline 3. Visual function questionnaire & 47.22 & 21.06 & & & - & $0.279^{\mathrm{b}}$ & $0.369^{a}$ \\
\hline 4. Mental composite score & 41.53 & 12.33 & & & & - & 0.026 \\
\hline 5. Physical composite score & 44.99 & 13.96 & & & & & - \\
\hline
\end{tabular}

${ }^{\mathrm{a}} \mathrm{p}<0.01 ;{ }^{\mathrm{b}} \mathrm{p}<0.05$.

Table 2: Stepwise regression analysis predicting satisfaction for $\mathrm{QoL}(\mathrm{n}=58)$.

\begin{tabular}{|c|c|c|c|c|c|c|}
\hline Step and predictor variable & $\mathbf{R}^{2}$ & $\mathbf{R}^{2}$ change & $\beta$ & $\operatorname{SE}(\beta)$ & Significance & $\mathbf{F}$ \\
\hline Step 1 & 0.096 & $0.096^{\mathrm{a}}$ & & & & 5.93 \\
\hline Mental health & & & $0.309^{\mathrm{a}}$ & 0.173 & 0.018 & \\
\hline Step2 & 0.131 & 0.035 & & & & 4.14 \\
\hline Mental composite score & & & 0.255 & 0.179 & 0.056 & \\
\hline Visual function questionnaire & & & 0.195 & 0.104 & 0.142 & \\
\hline Step3 & 0.196 & $0.065^{\mathrm{a}}$ & & & & 4.39 \\
\hline Mental composite score & & & 0.240 & 0.174 & 0.064 & \\
\hline Visual function questionnaire & & & 0.162 & 0.102 & 0.212 & \\
\hline Problem solving inventory & & & -0.259 & 0.106 & 0.041 & \\
\hline
\end{tabular}

${ }^{\mathrm{a} p}<0.01$.

( $p>0.05$ ). Finally, when the problem solving appraisal was entered, the model was significant, $F(3,54)=4.39, p<0.05$. The new model accounted for $20 \%$ of total variance and the $\mathrm{R}^{2}$ change was significant $(\mathrm{p}<0.05)$. Problem solving appraisal was the unique significant predictor $[\beta=-0.259$, $t(63)=-2.09, \mathrm{p}<0.05]$. A significant predictor of satisfaction for QoL experienced by individuals with vision loss was found which explained a relevant proportion of total variance which was problem solving appraisal; support was then provided for its role in mediating the relationship between limitations in health and in functional capacity older individuals recognize themselves after a moderate to severe visual loss.

\section{Discussion}

The main purpose of this study was to determine the extent to which various factors generally thought to be related to QoL are relevant in predicting satisfaction for QoL in individuals with visual loss.

The approach chosen here takes into account psychological dimensions. According to research literature domain-specific perceptions, behaviors and conditions are considered useful in providing information on person's well-being and the basis for assessing QoL-related personal outcomes $[47,30]$. Assessing QoL may require, then, analyzing the degree to which people living with a disabling condition have life experiences that they value, and include both experiences common to all humans and those unique to individuals.

In order to take into account research studies available in the literature and to provide answers to our research questions, three different levels of analysis were chosen: physical and mental disability, everyday visual ability in performing functional activities of daily living and, more importantly for the purpose of this study, a socio-cognitive dimension such as problem solving appraisal.

Correlation analyses showed a moderate association between, respectively, mental and physical health (SF-12) and independence in everyday life VFQ; between mental health, everyday independence and scores on PSI. These findings confirmed the relevance of questions addressed in the study and motivated a search for predictors of satisfaction for QoL at the three levels mentioned.

In the first step of the regression analysis the role of physical and mental health as predictors of satisfaction for QoL was analyzed but only the mental health score obtained by study participants was a significant predictor. When daily VFQ (measured taking into account near vision, distance vision, social functioning, peripheral and color vision) was entered into the analysis, an increase in 
the total variance was evidenced but again mental health was the unique-although marginal-predictor.

On the basis of studies reported in the literature [21, 34] one might expect a larger impact of physical and functional abilities in everyday tasks, insofar these individuals have a significant visual impairment which puts them at greater risk of problems in daily functioning. However, as these adults were not in an acute state, they may have already adapted to their living conditions and, as a result of resilience, flexibility and coping skills they may have the impact of the disabling condition they are experiencing on their own QoL $[10,11]$.

This finding leads to what we believe to be the central finding of the study, i.e. problem solving. In fact, when problem solving appraisal was entered, the new model accounted for $20 \%$ of total variance, with an additional $7 \%$ of the total variance. Problem solving appraisal was the unique significant predictor. Literature has already shown that problem solving may play a central role in adaptive responses evidenced in a large variety of stressful situations [48, 24]. Additionally, research involving adults with vision loss has already suggested a possible role of problem solving in finding solutions and in adapting to difficulties they encounter in everyday life specifically due to vision loss $[22,26,27,8]$. But despite empirical investigations demonstrating support for an association between social problem solving and health behaviors, these are to our knowledge the first data from persons with vision loss, concerning relations between problem solving abilities and QoL measured not only as health related behaviors but, instead, as satisfaction with QoL experienced in several different domains of everyday life. The finding obtained using the PSI [42, 43], one of the most widely used self-report inventories in the analysis of problem solving perception, underlines the role of individual's awareness and evaluation of his or her problem-solving abilities or style, the role of a global appraisal of the person with vision loss as a problem solver. This finding has several important implications. It underlines the relevance for older individuals to perceive themselves as able to solve everyday life problems and difficulties, i.e. to actively deal with and accommodate for life changes they need to manage, in order to maintain and possibly enhance QoL. From a theoretical point of view, it supports the notion that functional relationship between health status and satisfaction for QoL experienced must be understood in terms of approaches that incorporate psychological and socio-cognitive dimensions. Additionally, rehabilitation programs provided by services enable people who are visually impaired to learn how to use adaptive devices and techniques in order to independently perform in their everyday life. For instance, mobility interventions have been shown to positively influence satisfaction for functional capacity older individuals recognize themselves [49] as well as their satisfaction with self and health [50]. Although these goals are central, the efficacy of rehabilitation programs in overcoming the overall impact of vision impairment and improving satisfaction for QoL may be limited if other dimensions as well as developmental goals, available means to attain them and the increased restrictions people face as they grow older are not taken into account.

This study suggests, then, that rehabilitation counselors and therapists in their interventions should look beyond functional disability in daily activities and pay attention also to other dimensions amenable to intervention strategies, which are generally underestimated in vision rehabilitation programs; they consequently should also set specific actions tailored at promoting abilities relevant for coping and well-being. Problem solving should, then, become one of the main target of health professionals.

There are some limitations which must be considered when interpreting these findings. Subjects involved in the study do not represent, in fact, the whole range of individuals who have a visual disability; they rather represent old individuals with marked to severe vision loss.

Future research may address these limitations with purposeful sampling according to specific levels of loss, underlying causes and length of vision loss. This will also give us the opportunity to address in more detail and with more sophisticated techniques the role of specific components of problem solving appraisal.

This study has strengths nonetheless. It contributes to understanding factors which may affect QoL in individuals who experience a visual disability by considering both health-related and satisfaction for QoL experienced in different life domains; it is also based on a strong conceptualisation of QoL. It is the first study analyzing satisfaction with QoL in older adults with severe vision loss and relating this condition to problem solving. Results support that relevant and, at the same time, modifiable variables often targeted by health and rehabilitation interventions, such as problem solving appraisal, may constitute potential targets for interventions aimed at improving or maintaining well-being in persons with moderate to severe vision loss [51]. Taking into account the absence of clinically relevant effects on improving health-related QoL and the small effect for the "physical" QoL shown in a recent systematic review and meta-analysis on effectiveness of problem-solving therapy and interventions based 
on problem-solving principles (e.g. self-management programs based on problem-solving techniques), this study suggest the relevance of including non-health related measures of QoL when designing interventions with vision impaired individuals aimed at improving psychosocial outcome [52].

Acknowledgments: This paper is based on data collected within a joint research project supported by the Center for Disability, Rehabilitation and Inclusion (Centro di Ateneo Ricerca e Servizi Disabilità, Riabilitazione e Integrazione) of the University of Padova.

\section{References}

1. Crews JE, Campbell VA. Health conditions, activity limitations, and participation restrictions among older people with visual impairments. J Vis Impair Blind 2001;95:453-67.

2. Wahl HW, Schilling O, Oswald F, Heyl V. Psychosocial consequences of age-related visual impairment: comparison with mobility-impaired older adults and long-term outcome. J Gerontol B Psychol Sci 1999;54:304-16.

3. Good GA, La Grow S, Alpass F. An age-cohort study of older adults with visual impairments: Activity, independence and life satisfaction. J Vis Impair Blind 2008;102:517-27.

4. Knudtson MD, Klein BE, Klein R, Cruikshanks KJ, Lee KE. Agerelated eye disease, quality of life, and functional activity. Arch Ophthalmol 2005;123:807-14.

5. Noe G, Ferraro J, Lamoureux E, Rait J, Keeffe JE. Associations between glaucomatous visual field loss and participation in activities of daily living. Clin Experiment Ophthalmol 2003;31:482-6.

6. Pollard R, Miner Q, Cioffi J. Hearing and vision loss. In: Frank RG, Elliott TR, editors. Handbook of rehabilitation psychology. Washington, DC: American Psychological Association, 2000;205-34.

7. Burmedi D, Becker S, Heyl V, Wahl HW, Himmelsbach I. Emotional and social consequences of age-related low vision. Vis Impair Res 2002;47-71.

8. Kleinschmidt JJ. Older adults' perspective on their successful adjustment to vision loss. J Vis Impair Blind 1999;93:69-81.

9. Tsai SY, Chi LY, Cheng CY, Hsu WM, Liu JH, Chou P. The impact of visual impairment and use of eye services on health-related quality of life among the elderly in Taiwan: the Shihpai eye study. Qual Life Res 2004;13:1415-24.

10. Levasseur M, Desrosiers J, St-Cyr Tribble D. Do quality of life, participation and environment of older adults differ according to level of activity? Health Qual Life Outcomes 2008;6:1-11.

11. Renaud J, Levasseur M, Gresset J, Overbury 0, Wanet-Defalque MC, Dubois MF, et al. Health-related and subjective quality of life of older adults with visual impairment. Disabil Rehabil 2010;32: 899-907.

12. Ware JE, Sherbourne CD. The MOS 36-item short-form health survey (SF-36). Med Care 1992;30:473-83.

13. Mangione CM, Lee PP, Gutierrez PR, Spritzer K, Berry S, Hays RD. National eye institute visual function questionnaire field test $\mathrm{I}$. development of the 25 -item national eye institute visual function questionnaire. Arch Ophthalmol 2001;119:1050-8.
14. McKean-Cowdin R, Varma R, Wu J, Hays RD. Severity of visual field loss and health-related quality of life. Am J Ophthalmol 2007;143:1013-23.

15. Freeman EE, Munoz B, West SK, Jampel HD, Friedman DS. Glaucoma and quality of life: the Salisbury eye evaluation. Ophthalmology 2008;115:33-238.

16. McKean-Cowdin R, Varma Y, Wu J, Azen SP, Varma R. Impact of visual field loss on health-related quality of life in glaucoma: The Los Angeles Latino Eye Study. Ophthalmology 2008;115:941-8.

17. Mills RP, Janz NK, Wren PA, Guire KE. Correlation of visual field with quality-of-life measures at diagnosis in the collaborative initial glaucoma treatment study (CIGTS). J Glaucoma 2001;10:192-8.

18. McGwin G Jr, Xie A, Mays A, Joiner W, DeCarlo DK, Hall TA, et al. Visual field defects and the risk of motor vehicle collisions among patients with glaucoma. Invest Ophthalmol Vis Sci 2005;46:4437-41.

19. Freeman EE, Gange SJ, Muñoz B, West SK. Driving status and risk of entry into long-term care in older adults. Am J Public Health 2006;96:1254-9.

20. Lee DJ, Gómez-Marín O, Lam BL, Zheng DD. Glaucoma and survival: the National Health Interview Survey 1986-1994. Ophthalmology 2003;110:1476-83.

21. Lamoureux EL, Hassell JB, Keeffe JE. The determinants of participation in activities of daily living in people with impaired vision. Am J Ophthalmol 2004;137:265-70.

22. Dreer LE, Elliott TR, Fletcher D, Swanson M. Social problemsolving abilities and psychological adjustment of persons in low vision rehabilitation. Rehabil Psychol 2005;50:232-38.

23. Heppner PP, Krauskopf CJ. The integration of personal problem solving processes within counseling. Couns Psychol 1987;15:371-447.

24. Dixon WA, Heppner PP, Burnett JW, Anderson WP, Wood PK. Distinguishing among the antecedents, concomitants, and consequences of problem solving appraisal and depressive symptoms. J Couns Psychol 1993;40:357-64.

25. Heppner PP, Witty TE, Dixon WA. Problem-solving appraisal and human adjustment: A review of 20 years of research using the problem solving inventory. Couns Psychol 2004;32:344-428.

26. Brennan M, Cardinali G. Religiousness and spirituality in adaptation to vision impairment among middle-aged and older adults. In: Stuen C, editor. Vision rehabilitation: assessment, intervention and outcomes. Lisse, The Netherlands: Swets \& Zeitlinger 2000;645-9.

27. Upton LR, Bush BA, Taylor RE. Stress, coping, and adjustment of adventitiously blind male veterans with and without diabetes mellitus. J Vis Impair Blind 1998;92:656-65.

28. Nota L, Soresi S. Quality of life questionnaire. In: Soresi S, Nota L. Portfolio per l'assessment, il trattamento e l'integrazione delle disabilità. [Portfolio for the assessment, treatment and inclusion of disabled persons]. Giunti, Organizzazioni Speciali, Firenze 2007;230-56.

29. Shalock RL, Verdugo-Alonso MA, Braddock DL. Handbook on quality of life for human service practitioners. Washington, DC: American Association on Mental Retardation 2002.

30. Shalock RL, Verdugo MA, Bonham GS, Fantova F, Van Loom JV. Enhancing personal outcomes: organizational strategies, guidelines, and examples. J Policy Pract Intellect Disabil 2008;5:276-85. 
31. Nota L, Soresi S, Perry J. Quality of life in adults with an intellectual disability: the evaluation of quality of life instrument. J Intellect Disabil Res 2006;50:371-95.

32. Cummins RA. Moving from the quality of life concept to a theory. J Intellect Disabil Res 2005;49:699-706.

33. Wang $M$, Schalock R, Verdugo MA, Jenaro C. Examining the factor structure and hierarchical nature of the quality of life construct. Am J Intellect Dev Disabil 2010;115:218-33.

34. La Grow S, Alpass, F, Stephens, C, Towers, A. Factors affecting perceived quality of life of older persons with self-reported visual disability. Qual Life Res 2011;20:407-13.

35. Ware JE, Kosinski M, Keller S. SF-12: How to score the SF-12 physical and mental health summary scales. Lincoln, RI: Quality Metric. 1995/1998.

36. Apolone G, Mosconi P, Quattrociocchi L, Gianicolo EA, Groth N, Ware JE, et al. Questionario sullo stato di salute SF-12. Versione Italiana. Guerini e Associati Editore, Milano 2001.

37. Ware JE, Snow KK, Kosinski M, Gandel B. SF-36 health survey. Manual and interpretation guide. Boston: Nimrod, 1993.

38. Mingardi G, Apolone G. Misurare la Qualità della Vita correlata alla Salute (QdV-S) nel paziente uremico: una review dei concetti, dei metodi, degli strumenti disponibili e dei risultati. Giornale Italiano di Nefrologia, 2005;5:477-89.

39. Mangione CM, Lee PP, Pitts J, Gutierrez P, Berry S, Hays, RD. Psychometric properties of the national eye institute visual function questionnaire (NEI-VFQ). Arch Ophthalmol 1998;116:1496-504.

40. Margolis MK, Coyne K, Kennedy-Martin T, Baker T, Schein O, Revicki, DA. Vision-specific instruments for the assessment of health-related quality of life and visual functioning: a literature review. Pharmacoeconomics 2002;20:791-812.

41. Rossi GC, Milano G, Tinelli C. The Italian version of the 25 -item National Eye Institute Visual Function Questionnaire: translation, validity, and reliability. J Glaucoma 2003;12:213-20.

42. Heppner PP. The problem solving inventory: manual. Palo Alto, CA: Consulting Psychologists Press 1998.
43. Heppner PP, Petersen $\mathrm{CH}$. The development and implications of a personal problem solving inventory. J Couns Psychol 1982;29:66-75.

44. Soresi S, Mirandola M. PSI: problem solving inventory. Adattamento italiano: Organizzazioni Speciali, Firenze 1998.

45. Sgaramella TM, Soresi S, Ferrari L, Nota L. The role of executive functioning on quality of life perception in chronic unpredictable disabilities. J Intellect Disabil Res 2010;23:420.

46. SPSS Inc. Released. PASW Statistics for Windows, Version 22.0. Chicago: SPSS Inc. 2015.

47. Felce D, Perry J. Exploring current conceptions of quality of life: a model for people with and without disabilities. In: Renwick R, Brown I, Nagler M, editors. Quality of life in health promotion and rehabilitation: conceptual approaches, issues, and applications. Thousand Oaks, CA, US: Sage Publications, Inc; US 1996:172-186.

48. Heppner PP, Hillerbrand ET. Problem-solving training: Implications for remedial and preventive training. In: Snyder CR, Forsyth DR, editors. Handbook of social and clinical psychology: the healthy perspective. Elmsford, NY: Pergamon 1991:681-98.

49. La Grow S, Yeung P, Towers A, Alpass F, Stephens C. The impact of mobility on quality of life among older persons. J Aging Health 2013;25:723-36.

50. Yeung P, Towers A, La Grow S, Philipp M, Alpass F, Stephens C. Mobility, satisfaction with functional capacity and perceived quality of life (PQOL) in older persons with self-reported visual impairment: the pathway between ability to get around and PQOL. Disabil Rehabil 2015;37:113-20.

51. Sturrock BA, Holloway E, Keefe J, Hegel M, Casten R, Mellor D, et al. Rehabilitation staff perspectives on training for problemsolving therapy for primary care in a low vision service. $\mathrm{Br} J$ Vis Impair 2016;34:26-41.

52. Holloway EE, Xie J, Sturrock BA, Lamoureux EL, Rees G. Do problem-solving interventions improve psychosocial outcomes in vision impaired adults: a systematic review and meta-analysis. Patient Educ Couns 2015;98:553-64. 